\title{
Effects of fluoroscopy-guided conventional radiofrequency ablation in dissatisfied patients after total knee arthroplasty
}

\author{
Edip Gönüllü ${ }^{1}$, Sezgin Bahadır Tekin ${ }^{2}$ \\ ${ }^{1}$ Department of Algology, Dr. Ersin Arslan Education and Research Hospital, Gaziantep, Turkey \\ ${ }^{2}$ Department of Orthopaedic Surgery, Dr. Ersin Arslan Education and Research Hospital, Gaziantep, Turkey
}

Received: 2020-07-06.

Accepted: 2020-08-02

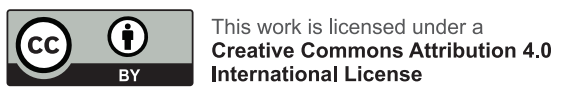

J Clin Med Kaz 2020; 5(59):34-37

Corresponding author:

Sezgin Bahadır Tekin.

E-mail: sezginbahadirtekin@gmail.com

\section{Abstract}

Objective: Osteoarthritis is a chronic progressive disease that can be treated with several conservative and surgical methods. One commonly used surgical method is total knee arthroplasty. However, some patients have persistent annoying pain afterward. The aim of our study was to investigate the effectiveness of radiofrequency treatment accompanied by fluoroscopy in patients who underwent total knee arthroplasty and had no other reason for their persistent pain.

Material and methods: Twenty-eight patients who had undergone total knee arthroplasty for osteoarthritis were retrospectively analyzed and included in the study. Patients who are dissatisfied after total knee arthroplasty procedure, were performed radiofrequency ablation by fluoroscopy. All patients were examined in terms of visual analog scale (VAS) and Western Ontario and McMaster Universities Osteoarthritis Index (WOMAC) scores preoperatively and 2 weeks and 1 and 3 months postoperatively.

Results: The VAS and WOMAC scores at postoperative week 2 and months 1 and 3 were statistically significantly different than the preoperative values for all patients $(P=0.001)$.

Conclusion: Patients with persistent pain after total knee arthroplasty obtained good results in terms of pain and knee function after conventional radiofrequency ablation accompanied by fluoroscopy but more studies with more patients are needed.

Key words: radiofrequency, total knee, dissatisfied patients

\section{Introduction}

Among the types of chronic arthritis, osteoarthritis is one of the most common complaints at admission to a hospital or a visit to an outpatient orthopedics and pain clinic. This condition, which restricts a patient from performing the activities of daily living and impairs the quality of life, causes irreversible joint damage. Among the several predisposing factors for osteoarthritis, foremost are obesity and a long life-span [1,2].

Although osteoarthritis can occur in the hips, knees, ankles, and shoulders, most patients visit the outpatient clinic complaining of knee pain. Patients also visit the clinic with complaints of limited ability to move, muscle weakness, and even the inability to walk. All these conditions can prevent a patient from walking, climbing stairs, or even sitting [2].

Treatment of osteoarthritis includes conservative exercises, weight loss, lifestyle changes, the use of nonsteroidal anti-inflammatory drugs (NSAIDs), and knee injections [3]. Depending on indications, patients with recalcitrant osteoarthritis can undergo arthroscopic debridement, high tibial osteotomy, unicondylar knee arthroplasty, and total knee arthroplasty. Total knee arthroplasty can be successful in patients for whom all other osteoarthritis treatments did not work. However, despite the outstanding results from total knee arthroplasty, some patients still have persistent pain after the procedure [4].

In addition to the above-mentioned treatments, radiofrequency (RF) ablation has become popular for relieving chronic pain from osteoarthritis [5]. It is also used to treat other chronic pain such as spinal pain, trigeminal neuralgia, and cancer pain. It was used safely in a patient group for which initial conservative treatment for knee osteoarthritis failed and in whom surgery could not be performed. 
The aim of our study was to investigate the effects of RF treatment on patients who still had pain following total knee arthroplasty that was performed after they did not respond to conservative treatment of their osteoarthritis and who frequently visited the outpatient clinic because of the persistent pain.

\section{Material and methods}

This study was a retrospective analysis of prospectively cooled data and has been approved by the IRB of the authors' affiliated institutions.

The study included 28 patients who had previously visited our clinic for osteoarthritis, did not respond to conservative treatment, had a total knee arthroplasty, and still had persistent pain. Data from the 28 patients were analyzed retrospectively. All patients were trained on the Visual Analog Scale (VAS) and the Western Ontario and McMaster Universities Osteoarthritis Index (WOMAC) before the procedure and were given VAS and WOMAC scores before surgery and 2 weeks, 1 month, and 3 months after surgery.

An additional criterion for a patient to be included in the study was that at least 6 months had to have passed after surgical treatment. We investigated X-ray films, infection parameters, and additional pain-inducing pathologies of our patients. The X-ray films were examined for component compatibility, relaxation, pathological fracture, and periprosthetic fracture. Possible infections were excluded by examining sedimentation, C-reactive protein values in blood samples taken from the patients, and infection parameters in synovial fluid.

After routine examination, the intervention area of all patients was sterilized with stain and draped. The patients were administered $1 \mathrm{mg}$ midazolam and $0.05 \mathrm{mcg}$ fentanyl under sedoanalgesia in the operating room before fluoroscopy. Local anesthesia was also administered to the intervention area. The patients were placed in a supine position with a small pillow placed under the popliteal fossa to support the knee. The tibiofemoral joint was visualized using fluoroscopy to detect the possible locations of the suprapatellar nerve in the middle of the lower end of the femur and the genicular nerves in the medial and lateral regions of the femur and the medial tibia. The lower femur and upper tibia were sterilized. Cutaneous and subcutaneous anesthesia was achieved with $2 \%$ lidocaine.

A 10-cm 22-gauge 10-mm active-tip radiofrequency thermocoagulation (RFT) cannula was inserted into each genicular and suprapatellar nerve with the help of anteriorposterior and lateral fluoroscopy images and the location of the cannula tip was monitored using anterior-posterior and lateral fluoroscopy. Subsequently, reactions to sensory stimulation with $50 \mathrm{~Hz}$ and motor stimulation with $2 \mathrm{~V}$ via the cannula were investigated. These reactions included the sensations of swelling, fullness, and change with sensory stimulation, and the sensations of kick and movement with motor stimulation via the cannula tip. After verifying the location of the cannula tip using stimulation, conventional RFT at $80^{\circ} \mathrm{C}$ (Celsius) was applied via the cannula for $90 \mathrm{~s}$. Complications and side effects (infection, bleeding, and neurological damage) that arose from RFT were recorded. Patients were asked not to undergo any other medical treatment or physiotherapy for pain for 3 months.

Pain felt by patients who underwent total knee arthroplasty and subsequently received RF treatment was measured 4 times using the VAS and WOMAC. The descriptive statistics for these measurements are expressed as mean \pm standard deviation, median (minimum-maximum). The difference between the measurements made at certain times was examined using analysis of variance on repeated measurements. Bonferroni correction was used for binary comparisons between measurement times to determine differential time levels in cases of statistically significant differences between repeated measurements. In all statistical analyses, the accepted significance level was $\mathrm{P}<0.05$ and the statistical software IBM SPSS 22.0 (IBM Corp, Armonk, NY, USA) was used.

\section{Results}

Twenty-eight female patients between 60 and 75 (mean=67.5) years of age participated in the study. The preoperative VAS and WOMAC scores of all patients were calculated. There was a statistically significant difference between the preoperative VAS $(\mathrm{P}=0.001)$ and WOMAC $(\mathrm{P}=0.001)$ scores of all patients and those scores 2 weeks, 1 month, and 3 months after surgery (Table 1).

\begin{tabular}{rll} 
Table 1 & \multicolumn{2}{l}{$\begin{array}{l}\text { Mean age of patients in malignant and benign } \\
\text { groups are shown. }\end{array}$} \\
& Preoperative & $\begin{array}{l}2 \text { weeks } \\
\text { postoperative }\end{array}$ \\
\multirow{2}{*}{ VAS } & $8.35 \pm 0.88$ & $4.9 \pm 2.9$ \\
& $8(7-10)$ & $5(0-9)$ \\
WOMAC & $61.7 \pm 19.9$ & $43.1 \pm 23.5$ \\
& $66(11.4-81.1)$ & $56.5(10-75)$ \\
\hline
\end{tabular}

${ }^{a}$ The values are the mean \pm standard deviation and median (min-max).

\section{Discussion}

To the best of our knowledge, our study is one of only a few that investigated the effect of RF treatment in patients dissatisfied with the results of knee arthroplasty. Preoperative and postoperative VAS and WOMAC scores were found to be statistically different. Other studies have had successful results with the application of RF to treat patients with osteoarthritis [69]. Our study of patients who underwent total knee arthroplasty for osteoarthritis showed that RF can be used as an alternative treatment in these patients who have persistent pain after surgery.

Because of its successful results, total knee arthroplasty is a preferred procedure for treating patients with end-stage osteoarthritis. However, there are still patients who have pain after the procedure even though the underlying cause is not obvious. One study found that approximately 53\% of patients who underwent total knee arthroplasty complained of postoperative pain, 7\% of whom reported that the postoperative pain was worse than the preoperative pain [10]. The cause of this pain, which negatively affects the quality of life of the patient, is often not found.

Daily painkillers, neuropathic pain medication, and exercise are some of the methods used to relieve pain after 
knee arthroplasty. Our study showed that RF is an alternative treatment for patients in whom these treatments have failed. Two studies have shown that RF treatment following knee arthroplasty improved knee scores and functions [11,12]. Our study also showed the positive effect of RF treatment on knee pain, with significant changes in VAS and WOMAC scores.

Figure 1 - Flouroscopic view of radiofrequency procedure.

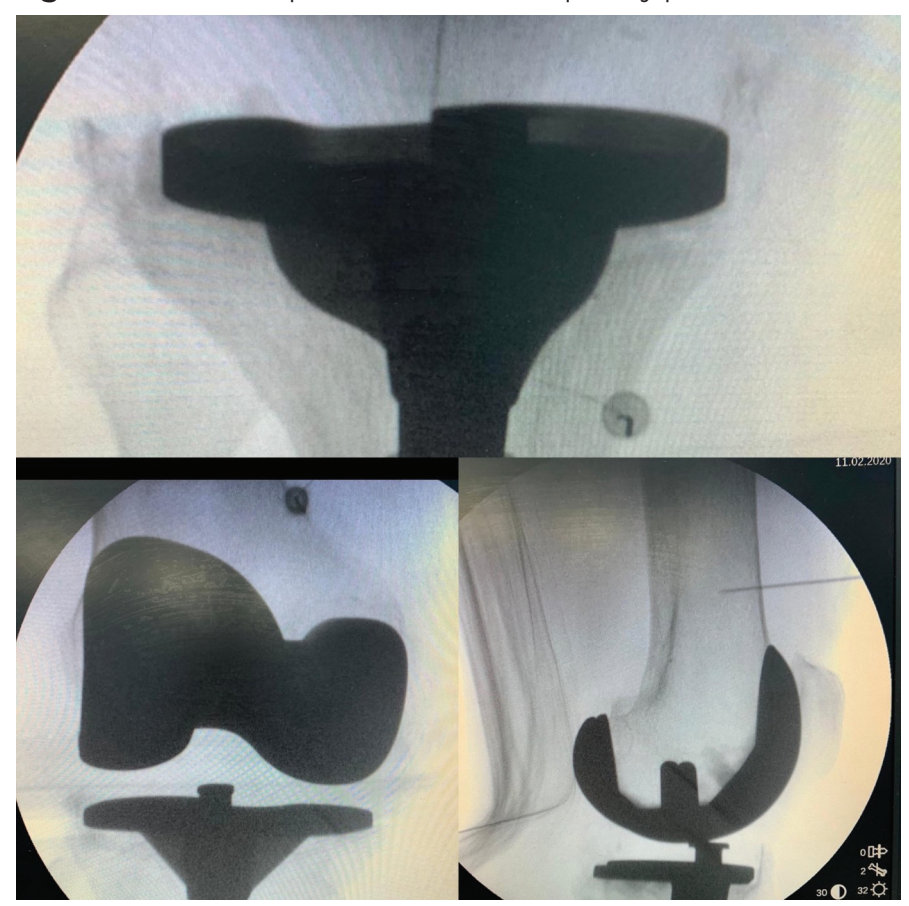

Radiofrequency treatment is based on the principle of using thermal energy for sensory innervation of nerves and distal nerve innervation [13]. In a randomized controlled study, Choi et al. showed that pain and function scores had improved in $60 \%$ of patients 3 months after treatment with RF [14]. Maria et al. showed a $50 \%$ decrease in pain in $64 \%$ of patients at the end of 6 months and in $32 \%$ of patients at the end of 1 year.

In RF treatment, the superomedial (SM), inferomedial (IM), and superolateral (SL) genicular nerves are targeted for ablation. The inferolateral nerve cannot be ablated because it is close to the common peroneal nerve $[15,16]$. In our study, those 3 nerves and the suprapatellar nerve were ablated. We did not ablate the inferior genicular nerve not to risk to damage the peroneal nerve.
Ultrasound is usually used as a guide to the nerves in studies investigating the effectiveness of RF treatment in patients who underwent knee arthroplasty. In our study, we performed RF treatment guided by fluoroscopy. However, studies have found that nerve tracks are more visible and the procedure is more effective when ultrasound is used $[17,18]$.

Elderly patients undergo total knee arthroplasty to treat osteoarthritis, which is accompanied by many comorbidities in this patient group. These patients will need additional medication, particularly NSAIDs. In our study, none of the patients had any side effects, which suggests that RF treatment is safe and causes no side effects in the elderly.

Our study has some limitations. Pain after total knee arthroplasty remains a problem and its cause in some patient groups has not been clarified. For this reason, we kept the patient cohort homogeneous, which limited the number of patients available. Second, this was a retrospective study. Third, we did not use a control group. Cooled RF is another method that was investigated by Bellini et al. They applied it to 9 patients who showed a significant increase in knee function and scores [19]. We were unable to use cooled RF in our hospital. Perhaps this method should be the subject of a future study. And we used fluoroscopy to perform the radiofrequency, ultrasound would be safer.

Another limitation is that we do not know what is the reason of knee pain after total knee arthroplasty exactly. To investigate where does pain come from, for example patellofemoral pain, percutaneous nerve around knee irritation or patient's character, may effect our results or may direct us the other treatment methods. The other limitations is the following time, especially 6 months follow-up and patient satisfaction has not been evaluated.

In this study we found that conventional RF ablation accompanied by fluoroscopy yielded better results in terms of pain and knee function for patients who had persistent pain after total knee arthroplasty. However, for a definite conclusion on efficacy, larger studies (with longer follow-up) are required.

Disclosures: There is no conflict of interest for all authors.

\section{Acknowledgements:}

Funding: none

\section{References}

1. Nguyen US, Zhang Y, Zhu Y, Niu J,Zhang B, Felson DT. Increasing prevalence of knee pain and symptomatic knee osteoarthritis: survey and cohort data. Ann Intern Med. 2011; 155 (11):725-732. https://doi.org/10.7326/0003-4819-155-11-201112060-00004

2. Losina E, Weinstein AM, Reichmann WM, Burbine SA, Solomon DH, Daigle ME, Rome BN, Chen SP, Hunter DJ, Suter LG, Jordan JM, Katz JN. Lifetime risk and age at diagnosis of symptomatic knee osteoarthritis in the US. Arthritis Care Res (Hoboken). 2013; 65(5):703-711. https://doi.org/10.1002/acr.21898

3. Karlsson J, Sjo̊̊Ngren LS, Lohmander LS. Comparison of two hyaluronan drugs and placebo in patients with knee osteoarthritis: a controlled, randomized, double- blind, parallel-design multicentre study. Rheumatology. 2002; 41(11):1240-1248 https:/doi. $\operatorname{org} / 10.1093 /$ rheumatology/41.11.1240

4. Lowry AM, Simopoulos TT. Spinal cord stimulation for the treatment of chronic knee pain following total knee replacement. Pain Physician. 2010; 13(3):251-256.

5. Vallejo R, Benjamin RM, Aliaga L. Radiofrequency vs. pulse radiofrequency: The end of controversy. Tech Region Anesth Pain Manage. 2010; 14(3):128-132. https://doi.org/10.1053/j.trap.2010.06.003

6. Choi WJ, Hwang SJ, Song JG, Leem JG, Kang YU, Park PH, Shin JW. Radiofrequency treatment relieves chronic knee osteoarthritis pain: A double-blind randomized controlled trial. Pain. 2011; 152(3):481-487. https://doi.org/10.1016/j.pain.2010.09.029

7. Iannaccone F, Dixon S, Kaufman A. A Review of Long-Term Pain Relief after Genicular Nerve Radiofrequency Ablation in Chronic Knee Osteoarthritis. Pain Physician. 2017; 20(3):E437-E444. https://doi.org/10.36076/ppj.2017.E444 
8. Gupta A, Huettner DP, Dukewich M. Comparative Effectiveness Review of Cooled Versus Pulsed Radiofrequency Ablation for the Treatment of Knee Osteoarthritis: A Systematic Review. Pain Physician. 2017; 20(3):155-171. https://doi.org/10.36076/ppj.2017.171

9. Karaman H, Tüfek A, Kavak G., Yildirim ZB, Uysal E, Celik F, Kaya S. Intra-articularly applied pulsed radiofrequency can reduce chronic knee pain in patients with osteoarthritis. J Chin Med Assoc. 2011; 74(8):336-340. https://doi.org/10.1016/j.jcma.2011.06.004

10. Ogalla IR, Martin AM, Pineda MMS, Huertas FR. Eficacia de la radiofrecuencia convencional de los geniculados para el tratamiento del dolor en la gonartrosis moderada- severa. Rev. Soc Esp Dolor. 2014; 21:212-218. https://doi.org/10.4321/S1134-80462014000400005

11. Protzman NM, Gyi J, Malhotra AD, Kooch JE. Examining the feasibility of radiofrequency treatment for chronic knee pain after total knee arthroplasty. PM R. 2014; 6:373-376. https://doi.org/10.1016/j.pmrj.2013.10.003

12. Ogalla IR, Martin AM, Pineda MMS, Huertas FR. Eficacia de la radiofrecuencia convencional de los geniculados para el tratamiento del dolor en la gonartrosis moderada- severa. Rev. Soc Esp Dolor. 2014; 21:212-218. https://doi.org/10.4321/S1134-80462014000400005

13. Mata J, Valentí P, Hernández B, Mir B, Aguillar. Study protocol for a randomised con- trolled trial of ultrasound-guided pulsed radiofrequency of the genicu- lar nerves in the treatment of patients with osteoarthritis knee pain. BMJ Open. 2017; 7(11): $\mathrm{e} 016377$

14. Choi WJ, Hwang SJ, Song JG, Leem JG, Kang YU, Park PH, Shin JW. Radiofrequency treatment relieves chron- ic knee osteoarthritis pain: a double-blind randomized controlled trial. Pain. 2011; 152(3):481-87. https://doi.org/10.1016/j.pain.2010.09.029

15. Franco CD, Buvanendran A, Petersohn JD, Menziez RD, Menziez LP. Innervation of the anterior capsule of the human knee: Implications for radiofrequency ablation. Reg Anesth Pain Med. 2015; 40(4): 363-68. https://doi.org/10.1097/AAP.0000000000000269

16. Yasar E, Kesikburun S, Kılıç C, Güzelküçük Ü, Yazar F, Tan AK. Accuracy of ultrasound-guided genicu- lar nerve block: A cadaveric study. Pain Physician. 2015; 18(5):899-904

17. Cheng PH, Kim HJ, Ottestad E, Narouze S. Ultrasound-guided injections of the knee and hip joints. Tech Reg Anaesth Pain Manag. 2009; 13:191-97 https://doi.org/10.1053/j.trap.2009.06.022

18. Huntoon MA: Ultrasound in pain medicine: Advanced weaponry or just a fad? Reg Anesth Pain Med. 2009; 34(5):387-88. https://doi. org/10.1097/AAP.0b013e3181b494f5

19. Patel N, Cohen SP, Response to: Cheng. Comparative outcomes of cooled versus traditional radiofrequency ablation of the lateral branches for sacroiliac joint pain. Clin J Pain. 2013; 29(2):132-137. https://doi.org/10.1097/AJP.0b013e31828c88e0 